\title{
Energy Efficiency of centralized and decentralized ventilation units in residential buildings - Specific Fan Power, Heat Recovery Rate, Shortcuts and Volume Flow Unbalances in Field tests
}

\author{
Alexander Merzkirch ${ }^{1}$, Stefan Maas ${ }^{1}$, Frank Scholzen $^{1}$, Daniele Waldmann ${ }^{1}$ \\ ${ }^{a}$ University of Luxembourg, Rue Coudenhove-Kalergi 6, Luxembourg
}

\begin{abstract}
The main objective in terms of energy efficiency of a ventilation system with heat recovery is to reduce the primary energy consumption of the building. Hence, the ratio between between saved and consumed energy should be greater than one and depends on various parameters. Fresh air supply can be decreased because of shortcuts within the system and unbalanced air flows, possibly resulting in lower heat recovery rates and unwanted ventilation losses. On the other hand, the energy consumption is often increased due to inefficient fan components or high pressure drops of inadequate components or design. These parameters among others were measured at 20 centralized and 10 to 67 (depending on the measured parameter) decentralized devices in field tests, with the goal of providing an overview of the performance of state-of-the-art ventilation systems in residential buildings. Nearly all devices showed shortcomings at one or more parameters. The values for shortcuts, heat recovery rates, sensitivity to pressure differences between in and outside and specific fan power in most cases differed from values provided by the manufacturers.

Keywords: Mechanical Ventilation, Specific Fan Power, Heat Recovery, Shortcuts
\end{abstract}

Preprint submitted to Journal of Energy $\&$ Buildings

March 6, 2015 


\section{Introduction}

Mechanical ventilation is a way to ensure good indoor air quality and to avoid moisture problems in air tight buildings, since it is very difficult or even impossible for the user to provide a sufficient amount of fresh air by natural ventilation. In terms of energy efficiency, the goal of mechanical ventilation is to transport the amount of air necessary to ensure good indoor air quality at the lowest possible energy consumption and to make use of heat recovery to decrease ventilation losses. Manufactures advertise high nominal values for these parameters, which may hold true under laboratory conditions, but are on site often lower than expected [? ? ? ]. To obtain real field data, measurements were carried out for 20 centralized devices and 10 to 67 (depending on the measured parameter) decentralized devices in residential buildings in Luxembourg.

\section{Objects}

Centralized ventilation systems use a ductwork to transport the supply and extract air, while decentralized systems, each device equipped with a heat exchanger and fans, are placed directly in the facade of the building. For decentralized systems, we can distinguish two different types. The first one being a pair-wise operating system with a regenerative heat exchanger and only one axial fan per device, counting for later named systems A and B. While the first device of a pair transports fresh air from outside to inside, the second device extracts air from the inside, which heats up the heat storage made out of aluminium or ceramic. Every 60 seconds (the cycle time depends on the device and manufacturer) the fans switch their directions and the stored heat from the outgoing air is transferred to the incoming air. The second decentralized concept (counting for systems C, D and E) is often called single room ventilation unit. Each unit can be seen as a small centralized system, since it provides supply air and extract air using two fans and a cross counterflow heat exchanger to transfer heat and two radial fans. All systems show advantages and drawbacks, the missing ductwork being the biggest advantage of the decentralized 
system, resulting in less pressure losses, easy installation and no maintenance of ducts. On the other hand, decentralized systems in general produce higher noise levels which often lead to user dissatisfaction [? ] and are more sensible to wind pressure on the facade.

\section{Theory \& Measurements}

Volume Flows. The volume flow was measured in extract and supply ducts using the constant emission tracer gas method [? ? ]. Conducting two successive measurements with two different injection points allows determination of the main air flows (see Fig. ??).

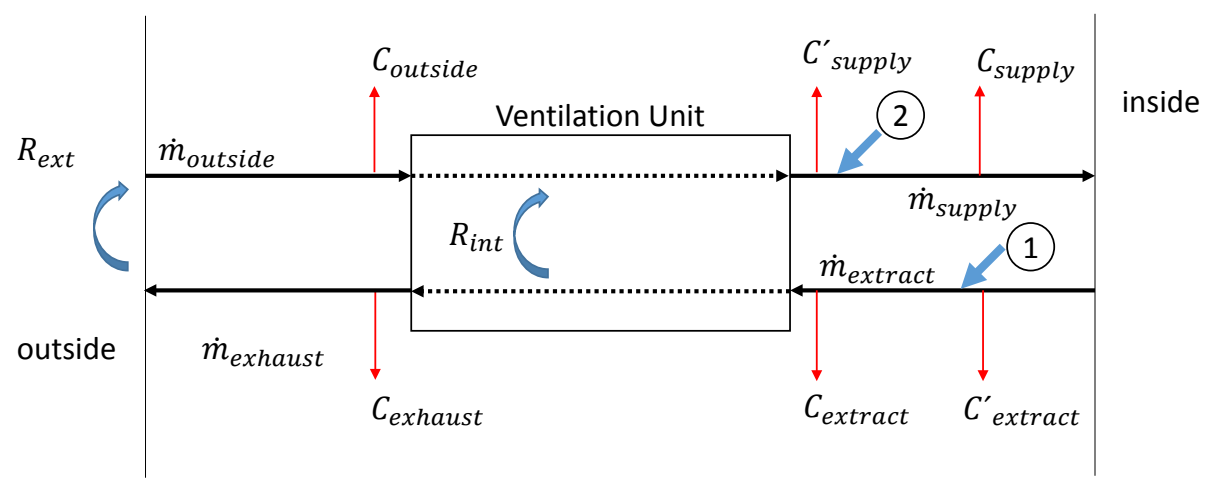

Figure 1: Airflows and tracer gas sample and injections points

The volume flows were calculated as follows:

$$
\begin{gathered}
\dot{m}_{\text {extract }}=\frac{\dot{I}_{1}}{C_{\text {extract }}-C_{\text {extract }}^{\prime}} \\
\dot{m}_{\text {supply }}=\frac{\dot{I}_{2}}{C_{\text {supply }}-C_{\text {supply }}^{\prime}}
\end{gathered}
$$

With:

$\dot{I}=$ tracer injection rate at point 1 or 2 respectively 
$C_{i}=$ tracer concentrations at respective points

To ensure low in-/exfiltration and high heat recovery rates, balanced supply and extract volume flows are of great importance. The mass balance of the air flows between a building and its surrounding is:

$$
\dot{m}_{\text {supply }}+\dot{m}_{\text {infiltration }}=\dot{m}_{\text {extract }}+\dot{m}_{\text {exfiltration }}
$$

If $\dot{m}_{\text {exract }}$ is not equal to $\dot{m}_{\text {supply }}$, there is unwanted in- or exfiltration, leading to unnecessary heating losses. Relative unbalances in percent between supply and extract air flow are calculated as follows:

$$
\text { Relative unbalance }=\frac{\dot{m}_{\text {supply }}}{\dot{m}_{\text {extract }}}
$$

Shortcuts. When assessing the volume flow one has to consider the effect of shortcut flows from extract to supply which decrease the amount of fresh air deliviered by the ventilation systems. There are two main shortcuts ratios, the internal shortcuts $\mathrm{R}_{\text {int }}$ and the external shortcut $\mathrm{R}_{\text {ext }}$. The possible internal shortcut from extract to supply air $\mathrm{R}_{\text {int }}$ can happen within the ventilation device, while the external shortcut can occur outside the building when part of the exhaust air is mixed into the fresh outside air. In reality, there exist several more shortcuts, e.g. from the device to the technical room or inside the device from supply back to extract, which were assumed zero. The concentration ratios below should be measured while injecting tracer gas at point $1\left(\dot{I}_{1}\right)$ :

$$
\begin{gathered}
R_{\text {ext }}=\frac{C_{\text {outside }}}{C_{\text {exhaust }}} \\
R_{\text {int }}=\frac{C_{\text {supply }}-C_{\text {outside }}}{C_{\text {exhaust }}-C_{\text {supply }}} \\
R_{\text {tot }}=R_{\text {ext }}+R_{\text {int }}
\end{gathered}
$$


When there are shortcuts $\left(\mathrm{R}_{\text {int }}\right.$ and/or $\left.\mathrm{R}_{\text {ext }}\right)$, the amount of fresh air in the supply air is reduced. Hence, we have to lower the volume flow $\dot{V}$ by the amount of recirculation flow, when calculating the specific fan power $\phi_{f a n}$.

Sensitivity to Differential Pressure. Since decentralized devices are installed in the facade of the building, their airflows are directly exposed to pressure differences induced by wind and/or stack effects. Previous studies have shown that supply and extract flows are highly sensitive to those pressure differences [6]. In order to measure the change in airflow, a simple set-up has been used during the field tests. In a room where a decentralized device was installed in the outer wall, the room door was replaced by a fan which was differential pressure controlled. As reference pressure the outside pressure was used. By varying the speed of the fan, over- and underpressure in steps of $2.5 \mathrm{~Pa}$ was induced in the room while simultaneously measuring the supply and extract air flow through the active ventilation device (see Fig. ??). All devices were set to their nominal flow levels. 


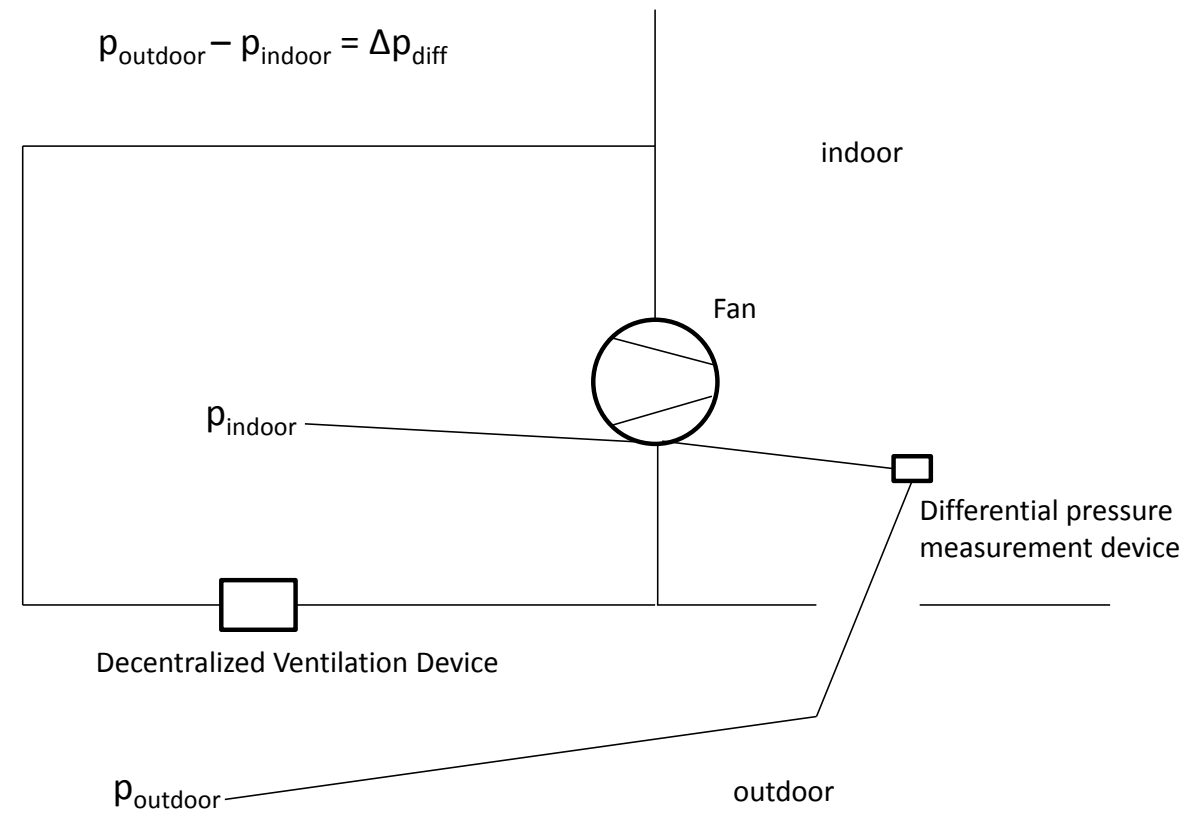

Figure 2: Measurement set-up for sensitivity to differential pressure

Specific Fan Power. The main parameter to assess the energy efficiency of air transportation is the specific fan power $\phi_{f a n}$, which is defined as the ratio between the power consumption $P$ of the device and the volume flow $\dot{V}$ induced by it. The consumed electrical energy is measured with a wattmeter which simultaneously captures current I, voltage U und the phase shift angle $\varphi$ between I and U.

$$
\begin{gathered}
P=U \cdot I \cdot \cos (\varphi) \\
\phi_{\text {fan }}=\frac{P}{\dot{V}}
\end{gathered}
$$

with:

$\phi_{\text {fan }}=$ specific fan power $\left[\mathrm{Wh} / \mathrm{m}^{3}\right]$;

$P=$ sower consumption of the ventilation device $[\mathrm{W}]$;

$\dot{V}=$ volume flow $\left[\mathrm{m}^{3} / \mathrm{h}\right]$. 
Temperature Change Rate. By the use of heat exchangers, the ventilation losses of a building can be decreased. The goal is to transfer as much heat from the extract air to the supply air as possible.

$$
\dot{Q}=\dot{m} \cdot c_{p l} \cdot\left(T_{\text {extract }}-T_{\text {exhaust }}\right)
$$

with:

$\dot{Q}=$ heat flow from extract to supply air $[\mathrm{W}]$

$\dot{m}=$ mass flow $[\mathrm{kg} / \mathrm{s}]$

$c_{p l}=$ specific heat capacity of air $[\mathrm{J} /(\mathrm{kgK})]$

$T=$ air temperature $[\mathrm{K}]$

The maximum heat flow possible is achieved when the exhaust air shows the same temperature as the outside air, which is therefore used as reference:

$$
\dot{Q}=\dot{m} \cdot c_{p l} \cdot\left(T_{\text {extract }}-T_{\text {outside }}\right)
$$

The temperature change rate can then be calculated as follows:

$$
\epsilon_{H R}=\frac{T_{\text {extract }}-T_{\text {exhaust }}}{T_{\text {extract }}-T_{\text {outside }}}
$$

Air temperatures have been measured at the same points were tracer gas samples were taken. For the decentralized devices which use a regenerative heat exchanger (Systems $\mathrm{A}$ and $\mathrm{B}$ ), the value for $\mathrm{T}_{\text {exhaust }}$ has to be averaged over a time $\tau$ larger than the time cycle, which is the duration of a supply or exhaust process:

$$
T_{\text {exhaust }}=\frac{1}{\tau} \int_{0}^{\tau} T_{\text {exhaust }}(t) d t
$$

For non-balanced volume flows, these efficiencies have to be interpreted correctly: If $\dot{m}_{\text {extract }} \dot{m}_{\text {supply }}$, the supply air shows high temperature levels but a part of the heat in the extract air is wasted since it could not be transferred to the supply air and $\epsilon_{H R}$ is low. If $\dot{m}_{\text {supply }} \dot{m}_{\text {extract }}$, the heat in the extract air can very well be transferred to the supply flow and $\epsilon_{H R}$ shows high values despite of the resulting supply air temperature being lower as with unbalanced flows. 
This temperature gap has then to be closed by the heating system. Hence, unbalanced volume flows lead to unwanted heat losses and temperature change rates which do not reflect the real behavior.

\section{Results}

Volume Flows. The mean measured air flow rate for centralized devices was 148 $\mathrm{m}^{3} / \mathrm{h}$, resulting in a mean air exchage rate caused by mechanical ventilation (without in-/exfiltration) of $0,371 / \mathrm{h}$ (see Fig. ??). The decentralized devices delivered a mean fresh air rate of around $30 \mathrm{~m}^{3} / \mathrm{h}$ per device. The total volume flow depends on the amount of devices installed in a dwelling (see Fig. ??). Within this field test, the mean air exchange rate in the dwellings equipped with decentralized systems was $0,36 \mathrm{~m}^{3} / \mathrm{h}$.

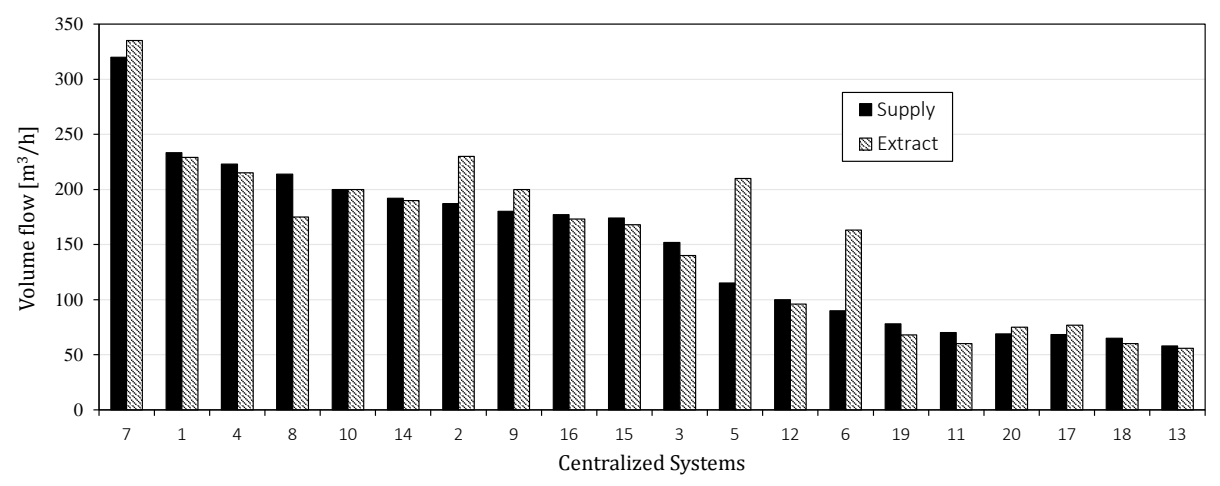

Figure 3: Air flows in 20 centralized devices 


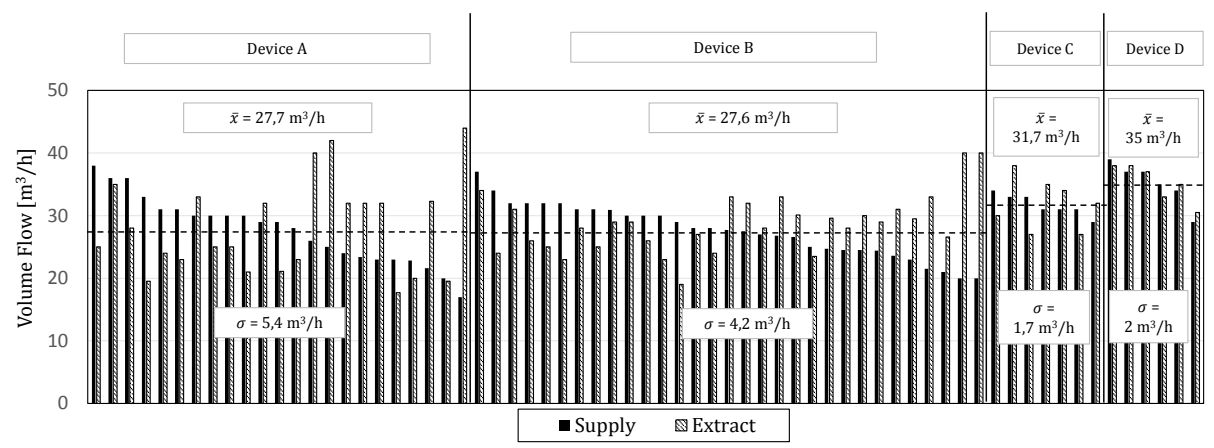

Figure 4: Air flows in 67 decentralized devices

Centralized and decentralized systems showed unbalances between supply and extract volume flows (see Fig. ??, ??). While only two of the centralized systems showed a deviation of more than $20 \%$, the decentralized systems A and $\mathrm{B}$ (with regenerative heat exchanger) showed high mean unbalances between 22 and $30 \%$. Devices of type $\mathrm{C}$ and D (with recuperative heat exchanger) showed much lower unbalances. These unbalances are of course only snapshots, depending on wind exposure and stack effects. The buildings were all placed in an urban surrounding with medium to low wind exposure.

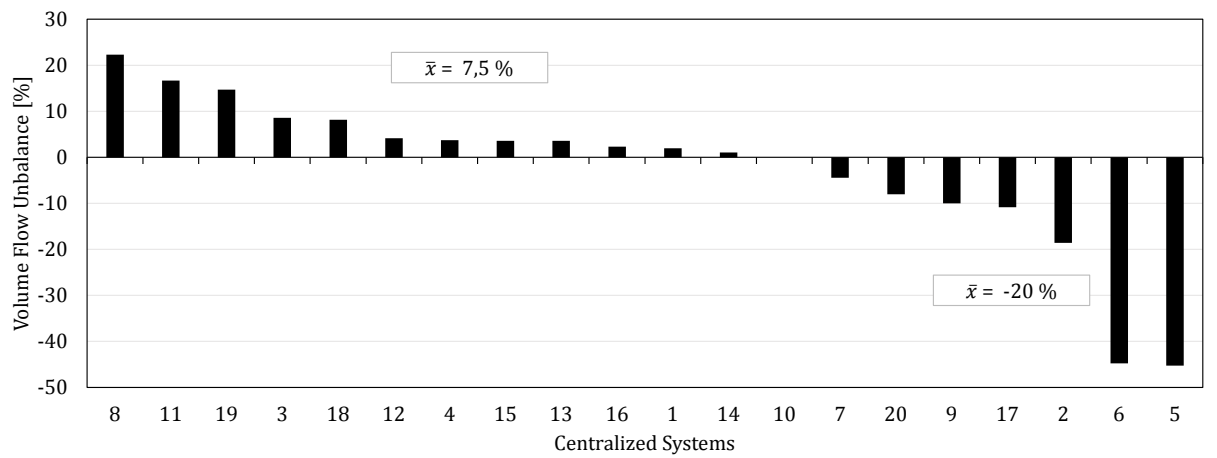

Figure 5: Volume flow unbalance in centralized devices 


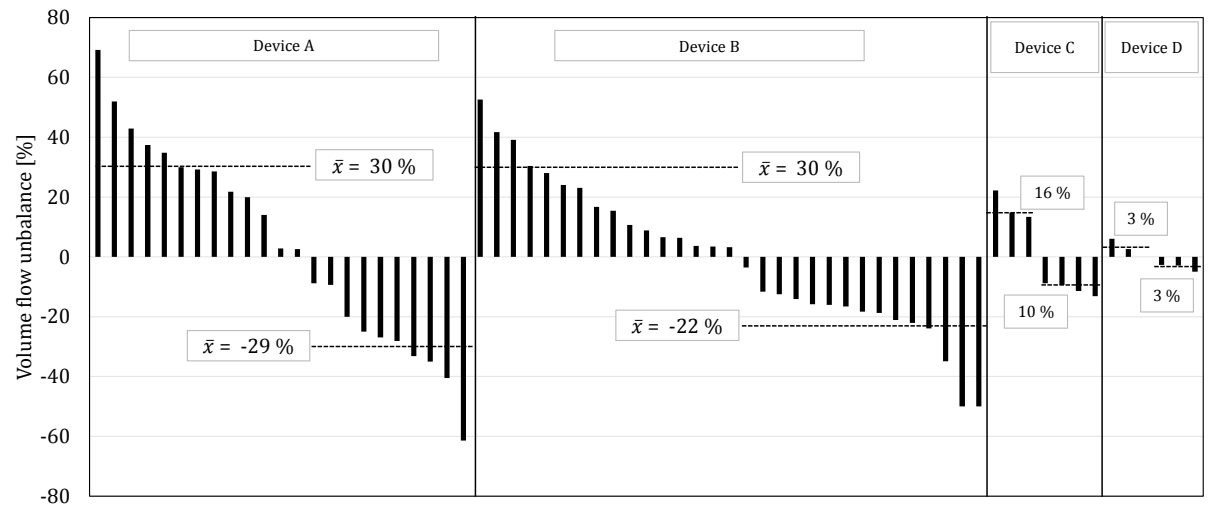

Figure 6: Volume flow unbalance in decentralized devices

Sensitivity to Differential Pressure. When inducing a differential pressure between inside and outside (see fig. ??), the decentralized systems A, B and C (device D could not be measured due to practical circumstances) showed increasing deviations between supply and extract flow. At a differential pressure of $10 \mathrm{~Pa}$ (the room is then under-pressurized), system A showed deviations of almost $100 \%$ from the nominal flow, system B around $50 \%$ and system C around $30 \%$, meaning that the supply rates were higher and the extract rates lower than the nominal flow rates (see Fig. ??). In cold winter days, this could lead to draught and also decrease the heat recovery efficiency. The lower value for system $\mathrm{C}$ can be explained by the higher pressure resistance of system $\mathrm{C}$ and radial fans which are more pressure stable. For centralized devices, the differential pressure induced by wind or stack effects is of much smaller influence because of the higher pressure level within a centralized system and only two openings to the outside. 


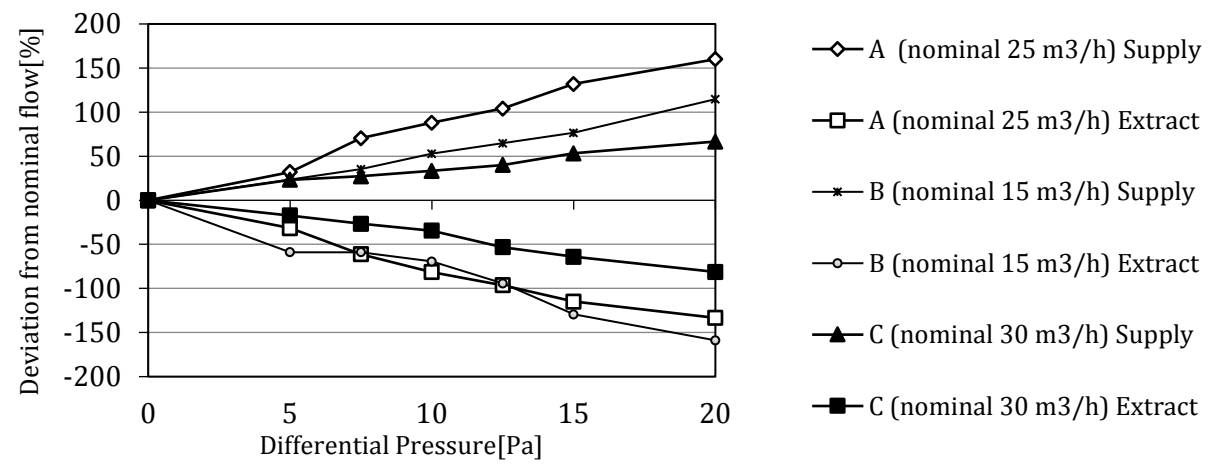

Figure 7: Sensitivity to differential pressure of decentralized devices

Shortcuts. The mean value for total shortcuts in centralized devices was 6,5 $\%$, which means that this part of the extract air is mixed into the supply air inside the device or outside the building (leaving out more possible shortcuts) (see Fig. ??). System Nr. 1 showed very high internal leakage. This was later explained by a defect heat exchanger which was not noticed by the user. The high recirculation rate resulted in a bad indoor air quality with $\mathrm{CO}_{2}$ concentrations of more than $2300 \mathrm{ppm}$ in the bedroom over night, despite of a measured supply rate for this room of $40 \mathrm{~m}^{3} / \mathrm{h}$. External recirculations were in most cases caused by inlets and openings placed too close to each other outside of the building and unfortunate wind directions leading part of the exhaust air to the outdoor air inlet. The high internal recirculation in system Nr. 4 could be explained through the functional principle of the heat exchanger since it was the only device with a rotary heat exchanger.

Decentralized devices of type C and D showed higher mean shortcuts of $13 \%$ (see Fig. ??), which mostly happened outside the building and can be explained by the placement of the inlet and opening too close to each other. Depending on wind intensity and direction, this effect can be in- or decreased. Devices of type $\mathrm{A}$ and $\mathrm{B}$ do not have recirculation per defintion of $\left(\mathrm{R}_{\text {int }}\right.$ and/or $\left.\mathrm{R}_{\text {ext }}\right)$. The case, where a part of the delivered fresh air could be extracted within the next cycle when the supply device turns into an extract device could not be measured 
via the tracer gas set-up due to the short time intervals of approximately one minute. The same kind of recirculation could happen at the outside of the building, resulting in external recirculation.

For both centralized and decentralized devices, shortcuts lead to a diminshed fresh air supply flow, making it necessary to increase the air flows to cover the demand. This again leads to higher power consumption of the fan and to higher noise levels which are in most cases the limitating factor especially for decentralized devices. While decentralized systems C and D and most centralized systems were able to deliver an airflow of $30 \mathrm{~m}^{3} / \mathrm{h}$ at noise levels around $25 \mathrm{~dB}(\mathrm{~A})$, the maximum volume flow of system $\mathrm{A}$ at this noise level was only $15 \mathrm{~m}^{3} / \mathrm{h}$, possibly resulting in decreased indoor air quality.

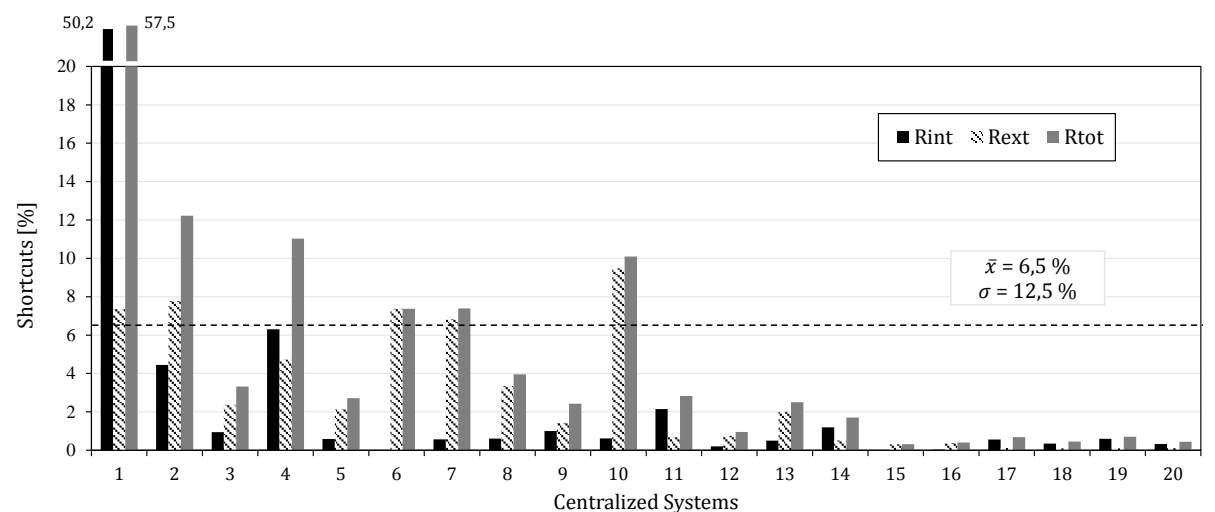

Figure 8: Shortcuts in centralized systems 


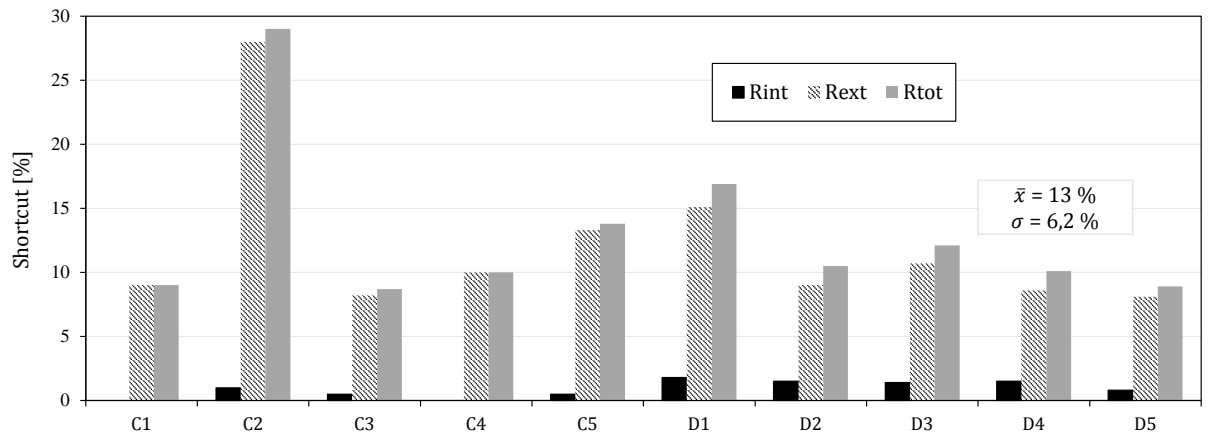

Figure 9: Shortcuts in decentralized systems

Specific Fan Power. The power consumption at standard level air flow was measured and the specific fan power calculated (eq. ??). In Figure ?? and ??, the results are shown for both centralized and decentralized devices. The grey upper end of the columns represent the surplus of fan power which would be necessary to make up for the recirculation from extract to supply for every unit. The mean value for the centralized devices is $0,475 \mathrm{Wh} / \mathrm{m}^{3}$ with a standard deviation of $0,37 \mathrm{Wh} / \mathrm{m}^{3}$. The often used limit for the specific fan power to label a centralized system as energy efficient is $0,4 \mathrm{Wh} / \mathrm{m} 3$. Without recirculation, 17 of the 20 centralized units fulfill this criteria, while considering recirculation only 13 systems do. The high value of system Nr. 1 was a result of high shortcuts of over $50 \%$. In case of system Nr. 11 it was a malfunction of the supply fan. 


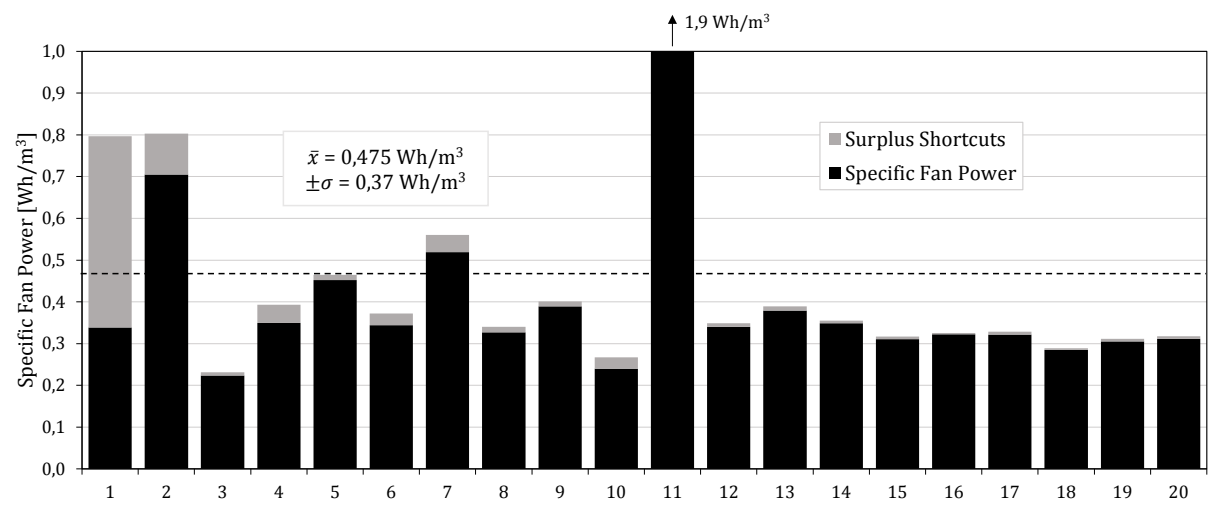

Figure 10: Specific fan power and surplus due to shortcuts of centralized devices

The mean value for the decentralized systems including the surplus for recirculation is $0,22 \mathrm{Wh} / \mathrm{m}^{3}$ only.

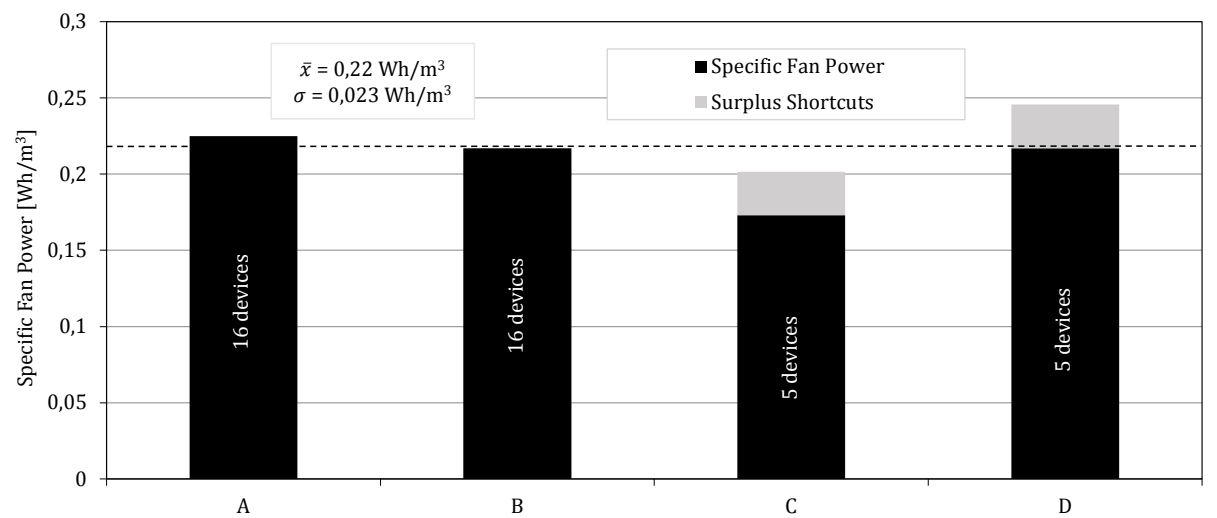

Figure 11: Specific fan power and surplus due to shortcuts of decentralized devices

Temperature Change Rate. In figures ?? and ?? the measured temperature change rates are shown for 11 centralized and 10 decentralized units. These values can only account for the time period when the measurements were taken. However, outdoor temperatures in all cases were between 0 and $4{ }^{\circ} \mathrm{C}$ and indoor temperatures between 20 and $22{ }^{\circ} \mathrm{C}$. The low value of system Nr. 1 is due 
to a defect heat exchanger. The low values of systems Nr. 2, 5 and 6 can be explained by the unbalance in volume flow and the resulting excess of extract air flow. The remaining temperature change rates lie within a range of about 70 and $80 \%$.

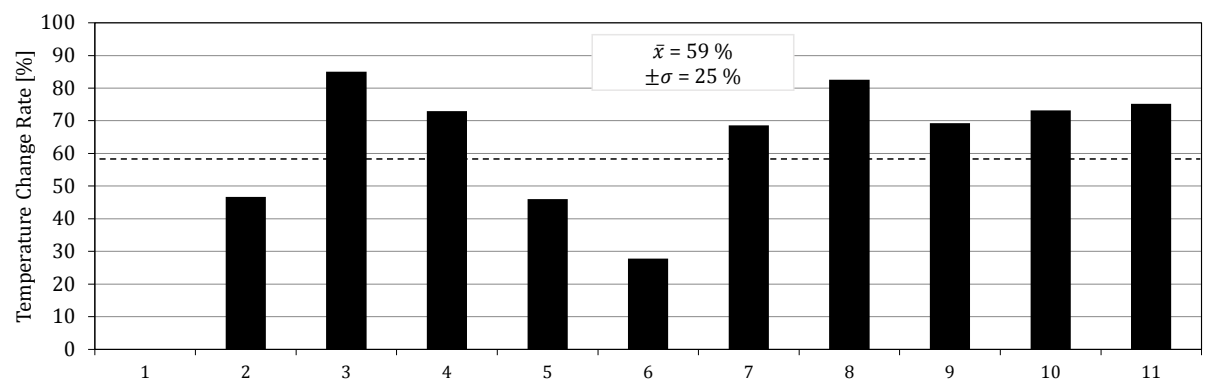

Figure 12: Temperature change rates of 11 centralized devices

Excluding system D.3 the temperature change rate of the decentralized units lie within a range of 70 and $80 \%$. In case of D.3, an opening was not properly installed during the mounting of the device, which was not noticed by the user.

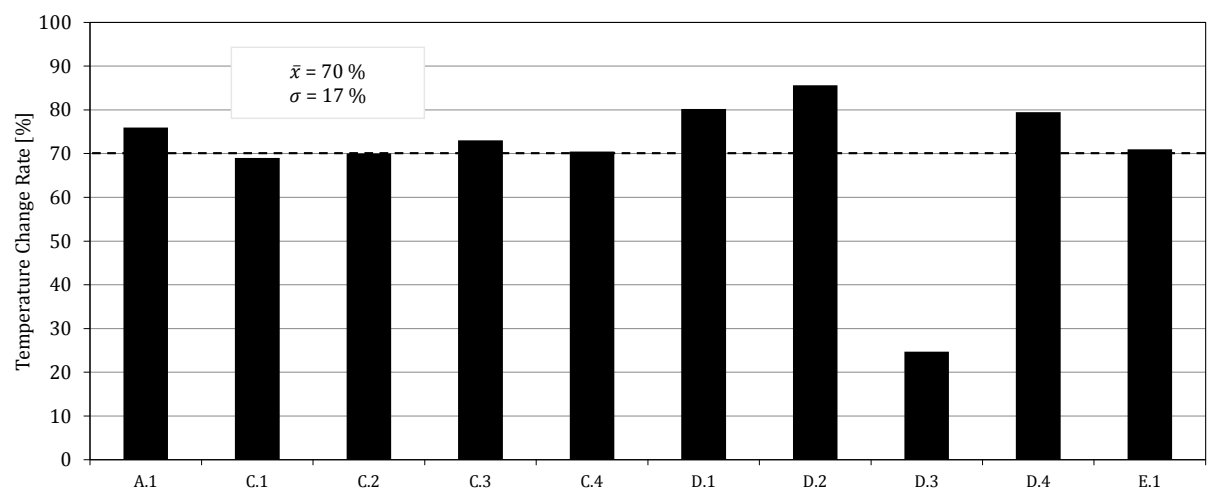

Figure 13: Temperature change rates of 10 decentralized devices

In figure ?? we can see the differences between the nominal temperature change rate given by the manufacturer and the measured rate. All of the de- 
vices show lower rates than measured under laboratory conditions with balanced airflows, in 5 of the cases even less than $50 \%$ of the nominal value.

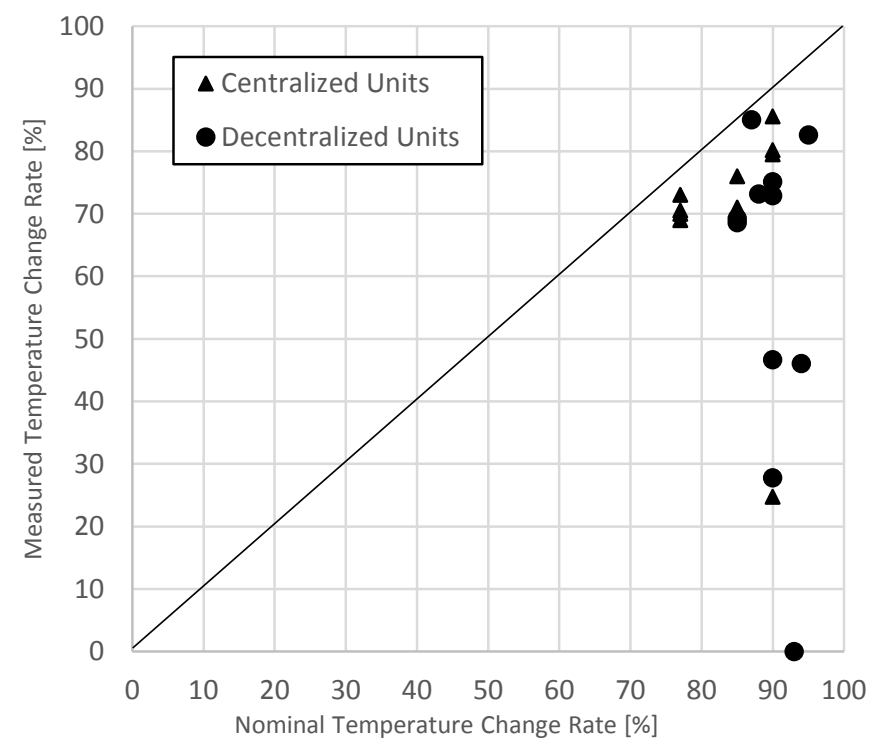

Figure 14: Measured temperature change rate and nominal values as measured in laboratory with balanced volume flows

\section{Discussion \& Conclusion}

Field measurements have shown practical values for centralized and decentralized units and revealed some possible shortcomings of the performance of the devices. High unbalance between supply and extract flow leads to lower heat exchange rates and in-/exfiltration, both resulting in higher ventilation losses. 7 of the 20 centralized systems, 42 of the 54 pair-wise decentralized systems (devices $\mathrm{A}$ and $\mathrm{B}$ ) and 6 of the 13 single room units (devices $\mathrm{C}$ and $\mathrm{D}$ ) showed deviations of more than $10 \%$. Follow up measurements confirmed the high sensitivity of decentralized devices to differential pressure, e.g. from wind pressure on the facades. Another reason for unbalances between air flows can simply be a hydraulically badly balanced system, e.g. a mistake during design, installation or commissioning. Especially the sensitivity of decentralized units 
has to be taken into account and should be object of additional measurements to address their heat exchange rate over a long term.

Measured mean total shortcuts of $6,5 \%$ for centralized devices and $13 \%$ for decentralized devices reduce the amount of fresh air delivered into the building und thus reduce indoor air quality. Decentralized devices showed almost no internal recirculation but encountered external shortcuts due to the opening outside, which are placed too close to each other. Avoiding or at least reducing these shortcuts should be part of future investigations. One problem is, that shortcuts usually remain unnoticed by the user, since they can only be measured using expensive tracer gas technology.

Decentralized systems showed a mean specific fan power of $0,22 \mathrm{Wh} / \mathrm{m}^{3}$ which was around $50 \%$ below the values for centralized units $\left(0,475 \mathrm{Wh} / \mathrm{m}^{3}\right)$. Despite of the lower efficiences of smaller fans compared to bigger ones, the missing ductwork leads to lower pressure losses for decentralized devices and thus to a lower power consumption. A mean value of $0,475 \mathrm{Wh} / \mathrm{m}^{3}$ for the centralized systems is about two times the values manufactures use for promotion. Of course, a ventilation device does depend on the ductwork and valve system installed, but assumptions of the manufactures concerning these external pressure losses do not seem to be realistic. The high mean standard deviation of $+/$ $0,37 \mathrm{Wh} / \mathrm{m}^{3}$ for centralized systems show, that the installation and operation situations can vary widely in practice. For decentralized devices, the standard deviation is much lower, since the installation situation is always the same for every device.

The temperature change rates are in all cases lower than nominal values of manufactures would let expect. While decentralized systems showed a mean temperature change rate of $70 \%$ with a mean standard deviation of $17 \%$, the values for centralized systems were much lower. A mean temperature change rate of $59 \%$ and a standard deviation of $25 \%$ show, that is difficult to transfer the high nominal values to practice.

The overall system functionality and efficiency shows strong interdependencies between all measured factors. Unbalanced volume flows lead to lower heat 
recovery rates and ventilation losses. Shortcuts lead to higher power consumption and ventilation losses or worse indoor air quality. Only a well-balanced and installed system where every single factor was taken into consideration can lead to good overall system performance, which particularly for centralized systems in residential buildings in practice does not seem to be the common case.

Acknowledgements. The authors acknowledge the high value contribution of the Ministry of Economy, Luxembourg and the Socit Nationale des Habitations Bon March (S.N.H.B.M.) which assisted with personnel, material, installations and gave valuable technical knowledge and assessment. Supported by the Fonds National de la Recherche, Luxembourg (PhD-FSTC-2015-05)

\section{Bibliography}

[1] C. A. Roulet, Real heat recovery with air handling units, Energy and Buildings (1) (2001) 495-502. doi:10.1016/S0378-7788(00)00104-3.

[2] A. Boerstra, J. Balvers, R. Bogers, R. Jongeneel, F. van Dijken, Residential ventilation system performance: Outcomes of a field study in the netherlands, 33rd AIVC conference proceedings (2012) Copenhagen, Denmark.

[3] H. Manz, H. Huber, D. Helfenfinger, Impact of air leakages and short circuits in ventilation units with heat recovery on ventilation efficiency and energy requirements for heating, Energy and Buildings 33 (2001) 133-139. doi: 10.1016/S0378-7788(00)00077-3.

[4] H. Manz, H. Huber, H. Schlin, A. Weber, M. Ferrazzini, M. Studer, Performance of single room ventilation units with recuperative or regenerative heat recovery, Energy and Buildings 31 (2000) 37-47. doi:10.1016/ S0378-7788(98) 00077-2.

[5] K. Cheong, Tracer gas technology for airflow measurements in hvac systems, International Journal of Energy Research 19 (1998) 1081-1093. doi:10. 1002/(SICI) 1099-114X (199612) $20: 12<1081::$ AID-ER236>3.0.CO;2-0. 
[6] M. Sandberg, H. Stymne, The constant tracer flow technique, International Journal of Energy Research 24 (1989) 209-219. doi:10.1016/ 0360-1323(89) 90034-6

[7] M. Sandberg, M. Sjberg, The use of moments for assessing air quality in ventilated rooms, Building and Environment 18 (1983) 181-197. doi:10. 1016/0360-1323(83)90026-4. 